\title{
Interventions to reduce acute and late adverse gastrointestinal effects of pelvic radiotherapy
}

DOI:

10.1002/14651858.CD012529

\section{Document Version}

Final published version

Link to publication record in Manchester Research Explorer

\section{Citation for published version (APA):}

Lawrie, T. A., Green, J. T., Beresford, M., Burden, S., Lal, S., Davidson, S. E., Henson, C. C., \& Andreyev, H. J. N. (2017). Interventions to reduce acute and late adverse gastrointestinal effects of pelvic radiotherapy. Cochrane Database of Systematic Reviews, 2017(2), [CD012529]. https://doi.org/10.1002/14651858.CD012529

\section{Published in:}

Cochrane Database of Systematic Reviews

\section{Citing this paper}

Please note that where the full-text provided on Manchester Research Explorer is the Author Accepted Manuscript or Proof version this may differ from the final Published version. If citing, it is advised that you check and use the publisher's definitive version.

\section{General rights}

Copyright and moral rights for the publications made accessible in the Research Explorer are retained by the authors and/or other copyright owners and it is a condition of accessing publications that users recognise and abide by the legal requirements associated with these rights.

\section{Takedown policy}

If you believe that this document breaches copyright please refer to the University of Manchester's Takedown Procedures [http://man.ac.uk/04Y6Bo] or contact uml.scholarlycommunications@manchester.ac.uk providing relevant details, so we can investigate your claim.

\section{OPEN ACCESS}




\section{Cochrane}

Cochrane Database of Systematic Reviews

\section{Interventions to reduce acute and late adverse gastrointestinal effects of pelvic radiotherapy (Protocol)}

Lawrie TA, Green JT, Beresford M, Burden S, Lal S, Davidson SE, Henson CC, Andreyev HJN

Lawrie TA, Green JT, Beresford M, Burden S, Lal S, Davidson SE, Henson CC, Andreyev HJN.

Interventions to reduce acute and late adverse gastrointestinal effects of pelvic radiotherapy.

Cochrane Database of Systematic Reviews 2017, Issue 2. Art. No.: CD012529.

DOI: 10.1002/14651858.CD012529.

www.cochranelibrary.com 
TABLE OF CONTENTS

HEADER . . . . . . . . . . . . . . . . . . . . . . . . . . . . . . . . . . . . 1

ABSTRACT . . . . . . . . . . . . . . . . . . . . . . . . . . . . . . . . . . . . . . . 1

BACKGROUND . . . . . . . . . . . . . . . . . . . . . . . . . . . . . . . . . . . .

OBJECTIVES . . . . . . . . . . . . . . . . . . . . . . . . . . . . . . . . . . . . . . . .

METHODS . . . . . . . . . . . . . . . . . . . . . . . . . . . . . . . . . . . . . . .

ACKNOWLEDGEMENTS . . . . . . . . . . . . . . . . . . . . . . . . . . . . . . . . . . . . . . . . . . . .

REFERENCES . . . . . . . . . . . . . . . . . . . . . . . . . . . . . . . . . . . . . . . . . 9

APPENDICES . . . . . . . . . . . . . . . . . . . . . . . . . . . . . . . . . . . . . 12

CONTRIBUTIONS OF AUTHORS . . . . . . . . . . . . . . . . . . . . . . . . . . . . . . . . . . . . . . .

DECLARATIONS OF INTEREST . . . . . . . . . . . . . . . . . . . . . . . . . . . . . . . . 17

SOURCES OF SUPPORT . . . . . . . . . . . . . . . . . . . . . . . . . . . . . . . . . . . . . . . . . .

Interventions to reduce acute and late adverse gastrointestinal effects of pelvic radiotherapy (Protocol)

Copyright $\odot 2017$ The Cochrane Collaboration. Published by John Wiley \& Sons, Ltd. 


\title{
[Intervention Protocol]
}

\section{Interventions to reduce acute and late adverse gastrointestinal effects of pelvic radiotherapy}

\author{
Theresa A Lawrie ${ }^{1}$, John T Green ${ }^{2}$, Mark Beresford $^{3}$, Sorrel Burden ${ }^{4}$, Simon Lal ${ }^{5}$, Susan E Davidson ${ }^{6}$, Caroline C Henson ${ }^{7}$, H. \\ Jervoise N Andreyev ${ }^{8}$ \\ ${ }^{1}$ Cochrane Gynaecological, Neuro-oncology and Orphan Cancer Group, Royal United Hospital, Bath, UK. ${ }^{2}$ Gastroenterology, Uni- \\ versity Hospital Llandough / Cardiff University, Vale of Glamorgan, UK. ${ }^{3}$ Department of Oncology and Haematology, Royal United \\ Hospitals Bath NHS Trust, Bath, UK. ${ }^{4}$ School of Nursing, Midwifery and Social Work, University of Manchester, Manchester, UK. \\ ${ }^{5}$ Intestinal Failure Unit, Salford Royal Foundation Trust, Salford, UK. ${ }^{6}$ Clinical Oncology, Christie Hospital NHS Foundation Trust, \\ Manchester, UK. ${ }^{7}$ Gastroenterology, Royal Bolton Hospital, Bolton, UK. ${ }^{8}$ Department of Gastroenterology, Royal Marsden Hospital, \\ London, London, UK
}

Contact address: Theresa A Lawrie, Cochrane Gynaecological, Neuro-oncology and Orphan Cancer Group, Royal United Hospital, Education Centre, Bath, BA1 3NG, UK. tess@lawrie.com.

Editorial group: Cochrane Gynaecological, Neuro-oncology and Orphan Cancer Group.

Publication status and date: New, published in Issue 2, 2017.

Citation: Lawrie TA, Green JT, Beresford M, Burden S, Lal S, Davidson SE, Henson CC, Andreyev HJN. Interventions to reduce acute and late adverse gastrointestinal effects of pelvic radiotherapy. Cochrane Database of Systematic Reviews 2017, Issue 2. Art. No.: CD012529. DOI: 10.1002/14651858.CD012529.

Copyright (C) 2017 The Cochrane Collaboration. Published by John Wiley \& Sons, Ltd.

\begin{abstract}
A B S T R A C T
This is a protocol for a Cochrane Review (Intervention). The objectives are as follows:

To determine which prophylactic interventions reduce the incidence, severity, or both of adverse gastrointestinal effects among adults receiving radiotherapy to treat primary pelvic cancers.
\end{abstract}

\section{B A C K G R O U N D}

\section{Description of the condition}

In 2012, 14.1 million people worldwide were diagnosed with cancer and 32.6 million people were living with cancer (within five years of diagnosis) (GLOBOCAN 2012). The number of people surviving cancer has increased significantly over the past few decades due to earlier diagnosis and advances in multimodal treatment (Andreyev 2012; CanRes 2016). Radiotherapy is a key component of anti-cancer treatment and approximately 4 out of every 10 people with cancer have radiotherapy as part of their treatment
(CanRes 2016). Whilst anti-cancer treatment is not always curative, it enables many people with a diagnosis of cancer to live for significantly extended periods.

Pelvic radiotherapy is used to treat various urological, gynaecological and gastrointestinal cancers, where it might be given alone as primary treatment, combined with chemotherapy, or given before or after surgery. During treatment, pelvic radiotherapy inevitably exposes the surrounding normal gastrointestinal tissue to some degree of radiation. Depending on various factors, such as the type of radiotherapy, the size and site of the treatment field, and the dose delivered, irradiation of normal tissue can lead to bowel injury (Andreyev 2007). In addition, other factors may influence the 
risk of bowel injury, including chemotherapy, previous abdominal surgery, smoking, co-existing medical conditions such as diabetes, hypertension and HIV, concurrent medication, genetic factors, and psychological issues (Andreyev 2007; Theis 2010).

Pelvic radiation disease (PRD), the term used for non-cancerous tissue injury secondary to radiotherapy, is increasingly being recognised as an unacceptable consequence of radiotherapy treatment (Morris 2015). Radiation-induced gastrointestinal tissue injury is mediated initially by an acute inflammatory process that leads to blood vessel damage, ischaemia (inadequate blood supply to the tissue), fibrosis (thickening and scarring), and loss of stem cells (Denham 2002). With repeated exposures over the course of radiotherapy treatment, the cycle of tissue injury and disrupted healing leads to progressive alteration in the affected tissue architecture and function. Gastrointestinal symptoms can be acute (occurring during radiotherapy or within three months), or chronic (persisting or appearing after three months) (Frazzoni 2015). Acute symptoms, including diarrhoea, abdominal pain, nausea, bloating, rectal bleeding, and urgency, typically begin during the second week of treatment and peak at four to five weeks (Khalid 2006). Acute symptoms usually resolve upon cessation of radiotherapy; however, they can necessitate dose reductions and treatment interruption, which can have a negative impact on the curative effect of treatment (Morris 2015; Stacey 2014). In addition, their occurrence may increase the risk of late gastrointestinal effects (Barnett 2011; O'Brien 2002). Chronic symptoms, including faecal incontinence, urgency, rectal bleeding, flatulence, and abdominal pain can follow acute symptoms or arise on their own some time later (Andreyev 2012). Incontinence can be particularly distressing and may be caused by injury to the anal sphincter and rectal tissue, leading to decreased rectal distensibility and storage capacity (Krol 2014). However, as widely separate parts of the gastrointestinal tract that lie in the path of the radiotherapy beam can be affected, symptoms associated with injury can have more than one physiological cause (Andreyev 2007). In addition, bile acid malabsorption, carbohydrate intolerances, and small bowel bacterial overgrowth occurring as a result of radiation-induced impaired bowel motility may exacerbate bowel symptoms (Andreyev 2007; Muls 2014). Chronic symptoms are very common, with up to $90 \%$ of patients reporting a permanent change in their bowel habit (Olopade 2005), and approximately 30\%, 40\% and 66\% of urological, gynaecological and colorectal cancer survivors experiencing chronic gastrointestinal symptoms that negatively affect their quality of life (Andreyev 2012).

\section{Description of the intervention}

Radiotherapy is a cancer treatment involving the use of high-energy radiation, usually $\mathrm{x}$-rays or similar rays (such as electrons or protons), to destroy cancer cells. The aim of modern radiotherapy is to ensure a high level of accuracy in tumour targeting, to reduce normal tissue exposure, and to minimise side effects (NCAT
2012). A variety of different strategies have been proposed to reduce its impact on normal tissues and prevent adverse gastrointestinal effects. These include improved radiotherapy delivery techniques, other aspects of radiotherapy delivery (e.g. timing of delivery, patient positioning or positioning devices), pharmacological interventions, and non-pharmacological interventions:

\section{Radiotherapy delivery techniques}

Conventional radiotherapy is delivered as external beam radiotherapy (EBRT). Conformal radiotherapy is the type of EBRT that is commonly used in high-income countries (CanRes 2016; CCS 2016). There are two types:

- 3D conformal radiotherapy (3D-CRT) is intended to improve tumour targeting and reduce the amount of radiation to the surrounding tissues by aiming shaped radiotherapy beams from several different directions at the tumour (CCS 2016). It uses pre-treatment imaging with computerised tomography (CT) or other types of scans to plan the radiotherapy treatment area in three dimensions (width, height and depth) matching the radiation beams to the 3D shape of the tumour. With 3D-CRT, the radiation beams are all the same intensity; and

- Intensity-modulated radiotherapy (IMRT) uses computerised methods to orientate multiple small beams of different intensities to the volume of tumour tissue that needs to be treated (CanRes 2016; NCAT 2012). IMRT may potentially conform more precisely to the tumour than 3D-CRT as it allows the dose of radiation to be adjusted for different parts of the treatment area and can create concave edges to reduce exposure to adjacent normal tissues. Volumetric modulated arc therapy (VMAT) is a type of IMRT in which the machine rotates around the patient during treatment, continuously adapting the radiation beam to the tumour volume as it moves.

It is currently unclear whether the occurrence or severity of adverse gastrointestinal effects in patients undergoing radiotherapy differs between these techniques.

\section{Image-guided radiotherapy (IGRT)}

IGRT includes any imaging performed at pre-treatment and treatment delivery that improves or verifies the accuracy of radiotherapy (NCAT 2012). It encompasses a wide range of techniques ranging from simple visual field alignment checks through to computerised tomography (CT) imaging that enables direct visualisation of the radiotherapy target volume and surrounding anatomy (NCAT 2012). If sufficiently accurate, IGRT has the potential to allow a reduction in the setup margin for a particular cancer site, reducing the radiation exposure to normal tissue. 4-Dimensional adaptive radiotherapy (4D-ART) combines IMRT and IGRT to take into account the 3D tumour shape over time (the fourth dimension) by tracking tumour motion during treatment (NCAT 2012). 


\section{Stereotactic body radiotherapy (SBRT)}

SBRT involves the use of a high and precise radiation dose in a small number of fractions (NCAT 2012). Radiotherapy beams are orientated from many different positions around the body to minimise the radiation dose to the surrounding tissues (CanRes 2016). SBRT is currently mainly used for small tumours of the brain, liver, lung and spinal cord; however, its use could potentially be extended to prostate cancer (Lischalk 2016, Moon 2017).

\section{Brachytherapy (BT)}

BT involves the placement of radioactive seeds within the tumour (interstitial brachytherapy), or within a cavity adjacent to the tumour (intracavitary brachytherapy) (Shadad 2013). Irradiation may be over a prolonged period of time (low dose) or temporary and short term (high dose). BT is often used in combination with EBRT. Where evaluated as an alternative to EBRT-based treatments, it has been associated with lower gastrointestinal toxicity (Nout 2010; Sorbe 2012).

Gastrointestinal injury is more likely with higher prescribed radiation doses (Barnett 2011; Michalski 2010). Therefore, limiting the volume of normal tissue exposed to intermediate (45 to $60 \mathrm{~Gy}$ ) and high doses (60 or more Gy) by using dose-volume constraints is an important part of treatment planning (Michalski 2010). Such parameters need adaptation and validation for different EBRT techniques (Michalski 2010). Irrespective of the radiotherapy technique used, effective immobilisation in both patient bony anatomy and internal organ motion during treatment is critical to avoid 'geographical miss', which will under dose the tumour and overdose the surrounding normal tissues (NCAT 2012).

\section{Other aspects of radiotherapy delivery}

\section{Patient positioning or positioning devices}

The position of a patient during radiotherapy delivery might influence the dose of radiation delivered to normal pelvic structures and subsequent gastrointestinal injury. A systematic review of prospective and retrospective studies of patient positioning and the use of belly boards suggests that delivering radiotherapy to patients positioned in the prone position (lying on their front rather that the supine position (lying on their back), and using positioning devices such as belly boards, displaces the small bowel away from the treatment field and can reduce the volume of small bowel irradiated (Weisendanger-Wittmer 2012).

\section{Timing of delivery}

Physiological 'clocks' that regulate the timing of physiological processes through gene expression exist in every organ and cell of the human body (Fuhr 2015). The circadian clock or day-night cycle is the core clock that might influence response to anti-cancer treatments and the development of treatment side effects (Fuhr 2015). Evidence from animal and human laboratory studies suggests that gastrointestinal cellular proliferation follows a circadian rhythm, with bowel mucosal proliferation (DNA synthesis) being greatest in the morning and lowest in the evening (Buchi 1991; Ijiri 1990). As proliferating cells are most radiosensitive, it is plausible that radiotherapy delivered in the morning may be more likely to cause damage to gastrointestinal mucosal cells than radiotherapy delivered in the evening. Findings from a clinical study of women receiving radiotherapy for cervical cancer, which found that severe diarrhoea occurred less frequently with evening radiotherapy than morning radiotherapy, appear to support this theory (Shukla 2010).

\section{Fractionation}

Curative pelvic radiotherapy treatment comprises a number of doses or fractions (usually 2 Gy or less per fraction) usually given over a period of about four to eight weeks to make up the total prescribed radiotherapy dose. Certain cancers such as prostate cancer have been shown to be more sensitive to fraction size than other tumours, behaving more like normal tissues; therefore, increasing the fraction size (hypofractionation) per treatment, which allows the total dose to be delivered in fewer treatments, might improve the treatment outcome or therapeutic ratio (Bossi 2016; Soh 2015). Several randomised trials of hypofractionation in prostate cancer have been conducted (Aluwini 2015; Arcangeli 2010; CHHiP 2016; Hoffman 2014; Norkus 2013; Pollack 2013). A 2015 systematic review concludes that moderate fractionation $(2.5$ to $4 \mathrm{~Gy}$ per fraction) is associated with late gastrointestinal toxicity similar to conventional fractionation; however, extreme fractionation ( 5 to 10 Gy per fraction) may have greater toxicity than conventional fractionation (Koontz 2015). Whilst potential benefits of hypofractionation include patient convenience, reduced treatment time and cost reduction (Moon 2017; Soh 2015), hypofractionation is not expected to reduce toxicity; rather, most trials hope to show that hypofractionation is safe and non-inferior to conventional fractionation in terms of toxicity. Therefore, we consider interventions dealing with altered fractionation schedules to be outside the scope of this review. A separate Cochrane review to evaluate the efficacy and toxicity of altered fractionation schedules for prostate cancer is currently underway (Soh 2015).

\section{Other interventions}

Various surgical techniques, such as the surgical placement of absorbable mesh slings to exclude the small bowel from the field of radiation, have been proposed to reduce the gastrointestinal effects of pelvic radiotherapy (Devereux 1988; Rodier 1991); however, the clinical effectiveness of such techniques remains uncertain (Stacey 2014). Using daily endorectal balloons filled with air 
or water might be beneficial for men undergoing prostate radiotherapy; findings from a non-Cochrane review suggests that such devices reduce prostate motion, improve dosimetry and reduce early gastrointestinal toxicity (Both 2012).

\section{Pharmacological interventions}

\section{Mucosal protectants}

Drugs that might protect the mucosa of the gastrointestinal tract from damage due to pelvic radiotherapy include sucralfate (a sucrose sulfate-aluminium complex) and various agents with antioxidant properties:

- Sucralfate binds to tissue proteins, creating a physical barrier over damaged mucosal surfaces and facilitating epithelial healing (Van de Wetering 2016). Low- to moderate-certainty Cochrane evidence suggests that it may be useful in the treatment of acute radiation-induced rectal bleeding, however, it remains unclear whether it can prevent rectal bleeding or other gastrointestinal symptoms of PRD when administered prophylactically (Van de Wetering 2016).

- Amifostine is thought to mediate a protective effect within normal cells by free-radical scavenging, DNA protection and repair acceleration, and induction of cellular hypoxia (Kouvaris 2007). It is used to protect renal cells from the effects of platinum chemotherapy in ovarian cancer, and in people undergoing radiotherapy for head and neck cancers to reduce xerostomia (dryness of the mouth) (Kouvaris 2007).

- Antioxidants, such as vitamins $\mathrm{C}, \mathrm{D}$, and $\mathrm{E}$, might reduce radiotherapy-induced injury by reducing antioxidant stress within gastrointestinal cells and facilitating tissue repair. Glutamine, a non-essential amino acid, selenium, and other agents with antioxidant properties could also potentially to be protective (Hall 2016).

\section{Anti-inflammatory agents}

5-aminosalicylates (e.g. sulfasalazine, balsalazide) are used in the treatment of certain inflammatory bowel conditions and, therefore, might have a role in preventing acute inflammatory gastrointestinal effects of radiation as suggested by the findings of some small trials (Jahraus 2005; Kilic 2001). Other anti-inflammatory agents that could potentially reduce gastrointestinal damage include other nonsteroidal anti-inflammatories and corticosteroids.

\section{Statins (3-hydroxy-methylglutaryl coenzyme-a reductase inhibitors) and angiotensin-converting enzyme (ACE) inhibitors}

A retrospective study of the effects of statins and ACE inhibitors on gastrointestinal effects in a cohort of people undergoing radiotherapy for pelvic malignancies reported better acute and long-term gastrointestinal symptom scores among those receiving statins (with or without ACE inhibitors) (Wedlake 2012); however, retrospective studies have a high risk of bias. Theoretically, statins might counteract some effects of radiation on normal tissues due to their vasculoprotective properties (Wang 2007). A study in rats showed that simvastatin commenced two weeks before irradiation was associated with less radiation injury, including improved mucosal preservation and reduced thickening of the intestinal wall (Wang 2007). In this study, the beneficial effects of simvastatin were greater at 26 weeks than at 2 weeks after radiotherapy.

\section{Other agents}

Octreotide is an analogue of the hypothalamic release-inhibiting hormone somatostatin (BNF 2016). It is mainly used to relieve symptoms associated with neuroendocrine tumours but it may have a role to play in reducing chemoradiotherapy-related diarrhoea. A 2014 review of octreotide for this purpose concluded that its role is more likely to be therapeutic than preventive (Sun 2014).

\section{Non-pharmacological interventions}

\section{Probiotics}

Probiotic preparations contain live and defined micro-organisms (usually lactobacilli and bifidobacteria) which, when administered in sufficiently large amounts, alter the host's microflora and potentially confer a health benefit (Kligler 2008). The potential mechanism/s of action of probiotics include epithelial cell proliferation, enhancing secretion of protective mucins, inhibiting bacterial translocation and stimulating the immune response (Van de Wetering 2013). Several clinical studies have investigated the role of probiotics for radiation-induced gastrointestinal injury, however, the role of probiotics to prevent or reduce PRD remains uncertain (Stacey 2014; Wedlake 2013).

\section{Nutritional interventions}

Malnutrition can occur as a consequence of radiotherapy-induced impaired gastrointestinal absorption and digestive functioning, and can also influence the development of gastrointestinal toxicity (Henson 2013). A 2013 Cochrane review evaluated the evidence on various nutritional interventions to improve nutritional status of people undergoing radiotherapy and found that dietary modification of fat, lactose, or non-starch polysaccharides (fibre) intake, or combinations of these dietary modifications, probably reduces diarrhoea at the end of radiotherapy (Henson 2013). However, another review concluded that there was insufficient evidence on nutritional interventions to guide clinical practice (Wedlake 2013). 


\section{Why it is important to do this review}

The focus on cancer and anti-cancer treatment is usually about survival. However, an increasing number of people survive cancer and have distressing side effects as a result of treatment. The impact of treatment on the cancer survivor's quality of life has been a much-neglected area of research in cancer treatment. In addition, clinicians tend to focus on ruling out cancer recurrence and progression at follow-up appointments, rather than asking about and addressing quality-of-life-related symptoms. These factors together suggest to cancer survivors that the side effects of radiotherapy treatment are a necessary trade-off with survival. Those affected may, therefore, be embarrassed to discuss their gastrointestinal symptoms with health care professionals, delay seeking help for them, and try to manage these problems themselves (Muls 2014).

To our knowledge, there is no comprehensive systematic review of prophylactic interventions to reduce the gastrointestinal toxicity of radiotherapy. Systematic reviews of endorectal balloons (Both 2012), patient positioning (Weisendanger-Wittmer 2012) and IMRT (Yu 2016) have included prospective and retrospective studies and have not graded the quality of evidence; two systematic reviews on nutritional interventions have reached slightly different conclusions (Henson 2013; Wedlake 2013); a systematic review of octreotide pooled data from prevention and treatment studies (Sun 2014), and a review of selenium supplements is out of date (Dennert 2006). These factors make interpretation of the evidence difficult. The aim of this review is, therefore, to systematically and critically appraise the evidence from randomised controlled trials on prophylactic interventions that might reduce the incidence or severity of gastrointestinal symptoms caused by pelvic radiotherapy, and bring them all together in one comprehensive review, in order to highlight those interventions that will lead to improvement in the quality of life of cancer survivors, and to direct the much-needed research in this field.

\section{O B J E C T I VES}

To determine which prophylactic interventions reduce the incidence, severity, or both of adverse gastrointestinal effects among adults receiving radiotherapy to treat primary pelvic cancers.

\section{METHODS}

\section{Criteria for considering studies for this review}

\section{Types of studies}

Randomised controlled trials (RCTs). We will exclude quasi-RCTs and cross-over designs.

\section{Types of participants}

Adults aged 18 years and older undergoing primary, adjuvant or neoadjuvant radiotherapy as part of anti-cancer treatment for primary pelvic cancers, including urological, gynaecological and gastrointestinal cancers. We will exclude studies of participants receiving palliative radiotherapy or radiotherapy for recurrent cancer, and studies of participants with stomas. Where studies are identified that include mixed groups that include some ineligible participants, we will attempt to extract data for the relevant participant subgroups only. If this is not possible, we will contact the authors to request these subgroup data. If these are not available or forthcoming, we will either exclude the study and explain our reason/s for doing so, or include the study if at least $80 \%$ of the participants are eligible, and indicate our concerns in the risk of bias assessment of the study. Included studies must have at least 20 participants.

\section{Types of interventions}

Interventions to prevent adverse gastrointestinal effects of pelvic radiotherapy including:

- Radiotherapy techniques (e.g. 3D-CRT, IMRT, BT);

- Interventions related to radiotherapy delivery including radiotherapy timing (e.g. evening radiotherapy schedules), patient positioning and positioning devices (e.g. belly boards), and other interventions (e.g. endorectal balloons);

- Pharmacological interventions (e.g. sucralfate, 5aminosalicylates, antioxidants, statins, ACE inhibitors); and

- Non-pharmacological interventions including dietary modification of macronutrients (carbohydrate, fats, protein, with or without micronutrients) and/or non-starch polysaccharides (dietary fibre), probiotics, and other interventions.

Comparators for radiotherapy techniques or timing will be other radiotherapy techniques or timing, whereas comparators for other types of interventions might be placebos, no intervention, or alternative interventions. Trials of interventions to treat acute symptoms will be excluded. We will also exclude trials of altered fractionation and dose escalation schedules, and trials of pre- versus postoperative radiotherapy regimen.

\section{Types of outcome measures}

Review outcomes include acute and late effects. Studies must evaluate at least one of the following outcome measures: 


\section{Primary outcomes}

1. Gastrointestinal (GI) symptom score, measured by a standardised scale, e.g. Inflammatory Bowel Disease Questionnaire-bowel function dimension (IBDQ-BD), Gastrointestinal Symptom Rating Scale (GSRS).

2. Moderate or severe GI symptoms (events), measured by a standardised scale, e.g. Common Terminology Criteria for Adverse Events (CTCAE 2010), IBDQ, GSRS, including:

- Overall events;

- Diarrhoea (the passing of frequent, loose stool);

- Faecal incontinence (leakage of stool from the rectum);

- Faecal urgency (a sudden, almost uncontrollable, need to pass stool);

- Rectal bleeding;

- Tenesmus (a feeling of incomplete evacuation and a constant urge to pass stool);

- Abdominal pain/cramps;

- Nausea;

- Vomiting;

- Flatulence; and

- Weight loss.

3. Quality of life (QoL), measured by a standardised scale, e.g. European Organisation for Research and Treatment of Cancer Quality of life Questionaire (EORTC QLQ-C30), Prostate Cancer Quality of Life Scale (PC-QOL), IBDQ.

\section{Secondary outcomes}

1. Toxicity-related discontinuation of the intervention;

2. Medication use for GI symptom control;

3. Patient satisfaction (as measured by investigators); and

4. Total mean bowel dose (Gy) (for studies evaluating radiotherapy techniques, patient positioning or positioning devices).

Where data are available, we will compare patient-reported outcomes measured during radiotherapy treatment, after radiotherapy treatment and up to three months (acute effects), between six and 12 months, between two and four years, and five or more years after treatment (late effects).

\section{Search methods for identification of studies}

\section{Electronic searches}

We will search the following databases:

- Cochrane Central Register of Controlled Trials

(CENTRAL), part of the Cochrane Library.

- MEDLINE (Ovid).

- Embase (Ovid).

- Cumulative Index to Nursing and Allied Health Literature (CINAHL) (Ovid).
- Cochrane Database of Systematic Reviews, part of the Cochrane Library.

We will not apply language restrictions to any of the searches. The MEDLINE search strategy is presented in Appendix 1. For databases other than MEDLINE, the search strategy will be adapted accordingly.

\section{Searching other resources}

We will search the following databases for ongoing trials:

- ClinicalTrials.gov (clinicaltrials.gov/)

- International Clinical Trials Registry Platform (ICTRP) ( apps.who.int/trialsearch/)

If ongoing trials that have not been published are identified through these searches, we will approach the principal investigators to ask for an update on the trial status and relevant data.

We will use the related articles feature of PubMed and handsearch the reference lists of included studies to identify newly published articles and additional studies of relevance. We do not plan to handsearch conference proceedings for conference abstracts because most relevant records will be identified by the electronic searches and any additional yield is likely to be negligible.

\section{Data collection and analysis}

\section{Selection of studies}

The Information Specialist at the Cochrane Gynaecological, Neuro-oncology and Orphan Cancer Group will download all titles and abstracts retrieved by electronic searching to Endnote ${ }^{\circledR}$ and remove duplicates and those studies that clearly do not meet the inclusion criteria. Two review authors (TL and another) will independently screen the remaining records independently. Due the wide scope of this review, the tasks of screening and selecting studies will be shared among several review authors. We plan to use Covidence (https://www.covidence.org/) to facilitate this study selection process. We will exclude those studies that clearly do not meet the inclusion criteria and we will obtain copies of the full text of potentially relevant references. Two review authors (TL and another) will independently assess the eligibility of the full text records. Disagreements will be resolved by discussion between the review authors concerned and, if necessary, at least one other review author will be consulted. Reasons for exclusion will be documented.

\section{Data extraction and management}

Data from included studies will be extracted by two review authors independently to a pre-designed data extraction form to include the following: 
- Author contact details;

- Country;

- Setting;

- Funding source;

- Inclusion and exclusion criteria;

- Study design, methodology;

- Study population and baseline characteristics:

- Total number of participants enrolled;

- Total number of participants analysed;

- Mean (SD) or median (range) age of participants;

- Numbers of male and female participants;

- Number of participants with co-existing medical conditions;

- Number of smokers (previous and current);

- Number of participants with urological,

gynaecological, colorectal, and other cancer;

- Number of participants who received primary,

adjuvant, or neoadjuvant radiotherapy, or other anti-cancer treatment;

- Radiotherapy type, total dose and volume; and

- Baseline gastrointestinal symptoms and/or symptom scores;

- Intervention details:

- $\quad$ Type of intervention, i.e. radiotherapy techniques, pharmacological interventions, treatment schedules, patient positioning and positioning devices, nutritional and other interventions, including dose, frequency, and timing;

- Type of comparator, e.g. other intervention, no active intervention (observation or placebo);

- Risk of bias in study (see below);

- Duration of follow up;

- Primary outcome/s of the study;

- Review outcomes:

$\circ$ time-point/s for collection;

o type of scale used, scale thresholds used for determining severity of symptoms;

- For dichotomous outcomes (e.g. number of participants with moderate or severe gastrointestinal symptoms), the number of participants in each treatment arm who experienced the outcome of interest and the number of participants assessed at the time-point;

- For continuous outcomes (e.g. QoL scores), the value and standard deviation of the outcome of interest and the number of participants assessed at the relevant time-point in each treatment arm. We will also extract change-from-baseline score data where reported;

- We will extract adjusted and unadjusted statistics in accordance with inclusion criteria. Where possible, all data extracted will be those relevant to an intention-to-treat analysis, in which participants were analysed in the groups to which they were assigned. We will resolve differences between reviewers by discussion or by appeal to a third review author when necessary;
- We anticipate inter-study heterogeneity in the measurement and reporting of gastrointestinal symptoms. Therefore, where available, we will extract and analyse both dichotomous and continuous data for this outcome. GI effects will be considered to be 'severe' if they are classified as grade 3 or higher according to Common Terminology Criteria for Adverse Events (CTCAE 2010), or determined to be 'severe' by investigators according to investigator-interview or self-report questionnaires, such as the Gastrointestinal Symptom Rating Scale (GSRS). Similarly, we will consider 'moderate' adverse effects to be the equivalent of CTCAE grade 2 or as determined by investigators according to the measurement scale used. In the event that symptom events are reported but not graded, we will extract the available symptom data from the report and note the unclear or higher potential risk of bias for these outcomes.

\section{Assessment of risk of bias in included studies}

We will assess the risk of bias of included studies using Cochrane's tool and the criteria specified in the Cochrane Handbook for Systematic Reviews of Interventions (Higgins 2011). This includes assessment of:

- random sequence generation;

- allocation concealment;

- blinding of participants and healthcare providers;

- blinding of outcome assessors;

- incomplete outcome data (more than $20 \%$ missing data considered high risk);

- selective reporting of outcomes; and

- other possible sources of bias.

For details, see Appendix 2.

Blinding of participants and healthcare providers may not be feasible for certain interventions, e.g. radiotherapy techniques or patient positioning. If a study is assessed as being at high risk of bias for this domain due to a lack of this type of blinding, but low or unclear risk for the other domains, we will judge the study to be at low or unclear risk of bias overall. Several outcomes will be measured by self-reported scales. In general, we will not consider self-reported symptom and QoL outcomes to represent a high risk of bias in the context of this review, as these are our primary outcomes. However, where the outcome has been investigator-assessed and where the investigator has been aware of the group allocation, we are likely to assess the study as being at high risk of bias for the 'blinding of outcome assessor' domain and at a potentially high risk of bias overall.

Two review authors will apply the 'Risk of bias' tool independently and differences will be resolved by discussion or by appeal to a third review author. We will summarise judgements in risk of bias tables along with the characteristics of the included studies. Results of meta-analyses will be interpreted in light of the overall risk of bias assessment. 


\section{Measures of treatment effect}

- For dichotomous outcomes (e.g. severe gastrointestinal symptoms), we will calculate the effect size as a risk ratio (RR) with its $95 \%$ confidence interval (CI).

- For continuous outcomes (e.g. QoL scores) we assume that study authors will use different measurement scales, therefore, we plan to estimate the standardised mean difference (SMD) and its 95\% CI using the pooled data. However, if the same measurement scale is used, we will estimate the mean difference (MD) and its 95\% CI. If studies do not report total values but, instead, report change-from-baseline outcomes, we will combine these change values with total measurement outcomes by using the (unstandardised) mean difference method in RevMan (RevMan 2014). We will use subgroups to distinguish between MDs of change scores and MDs of final values, and pool the subgroups in an overall analysis (Higgins 2011).

- We will not be using time-to-event data.

\section{Unit of analysis issues}

Two review authors (TL and another) will review unit of analysis issues according to Higgins 2011 and differences will be resolved by discussion. These include reports where:

- Groups of individuals are randomised together to the same intervention (i.e. cluster-randomised trials); or

- There are multiple observations for the same outcome (e.g. repeated measurements with different scales or at different timepoints, recurring events).

We will discuss the implications of our unit of analysis decisions in the section on 'Potential biases in the review process' of the 'Discussion'.

\section{Dealing with missing data}

In the event of missing data, such as missing standard deviations, we will obtain these where possible using calculations provided in the Cochrane Handbook for Systematic Reviews of Interventions (Higgins 2011) or by writing to authors to request the data. We will describe in the characteristics of studies tables how any missing data were obtained.

\section{Assessment of heterogeneity}

We will assess heterogeneity between studies in each meta-analysis by visual inspection of forest plots, by estimation of the percentage heterogeneity between trials which cannot be ascribed to sampling variation (Higgins 2003), by a formal statistical test of the significance of the heterogeneity (Deeks 2001), and, where possible, by subgroup analyses. If there is evidence of substantial heterogeneity, the possible reasons for this will be investigated and reported.

\section{Assessment of reporting biases}

If there are 10 or more studies in meta-analyses we will investigate reporting biases (such as publication bias) using funnel plots. We will assess funnel plot asymmetry visually. If asymmetry is suggested by a visual assessment, we will perform exploratory analyses to investigate it.

\section{Data synthesis}

We will conduct meta-analyses if participants, interventions, comparisons and outcomes are judged to be sufficiently similar to ensure an answer that is clinically meaningful. We will use the random-effects model with inverse variance weighting for all metaanalysis due to anticipated heterogeneity in the study population and outcome measurements. If any trials have multiple treatment groups, we will divide the 'shared' comparison group into the number of treatment groups and comparisons between each treatment group and treat the split comparison group as independent comparisons. We will perform meta-analysis of the results assuming that included studies are sufficiently similar for the findings to be clinically meaningful.

\section{Summary of findings table and results reporting}

Based on the methods described in Chapter 11 of the Cochrane Handbook for Systematic Reviews of Interventions (Higgins 2011), we will prepare a summary of findings $(\mathrm{SoF})$ table to present the results of the meta-analyses. (See Appendix 3 for example SoF). Where there are sufficient data, we will present results for the following outcomes for early (at end of treatment and/or up to three months) and late effects (six months to one year, two to four years, and five year time-points):

- Mean GI symptom score;

- Moderate or severe GI events;

- Moderate or severe diarrhoea; and

- QoL.

For each assumed risk cited in the tables, we will provide a source and rationale, and the GRADE system will be used to rank the quality of the evidence using GRADEprofile (GRADEpro) software (Schünemann 2011). Where the evidence is based on single studies, or where there is no evidence on a specific outcome, we will include the outcome in the SoF tables and grade or explain accordingly. Two authors will independently grade the evidence. We will consider downgrading evidence from single studies for imprecision related to small sample size. Differences will be resolved by discussion and, if necessary, by involving a third review author. We will report the results of the meta-analyses in the text based on the guidance from the Cochrane Effective Practice and Organisation of Care group on review results reporting and interpretation (EPOC 2015). 


\section{Subgroup analysis and investigation of heterogeneity}

Provided there are sufficient data, we will perform subgroup analysis by the type of outcome scale used (patient-reported and clinician-reported scales), the type of cancer (urological, gynaecological, and colorectal), and the radiotherapy regimen (by fractionation size of 2 Gy or less versus larger fractionation sizes, and total dose, or both). Formal tests for subgroup differences will be used to determine whether the effect of interventions differ according to these subgroups. Depending on these findings, we will consider whether an overall summary is meaningful. We will consider factors such as age, gender, type and dose of radiotherapy, previous treatments (abdominal surgery and chemotherapy, or both), and study risk of bias assessment in interpretation of any heterogeneity. If we identify substantial heterogeneity, we will investigate the source using sensitivity analyses.

\section{Sensitivity analysis}

We will perform sensitivity analysis by excluding studies at high risk of bias overall, and those at unclear or high risk of bias for spe- cific outcomes (e.g. if we have included data on ungraded symptom events). We will also perform sensitivity analysis to investigate substantial heterogeneity identified in meta-analyses of primary outcomes.

\section{ACKNOW LEDGEMENTS}

We thank Jo Morrison for clinical and editorial advice, Jo Platt for designing the search strategy, and Gail Quinn, Clare Jess and Tracey Harrison for their contributions to the editorial process.

This project was funded by the National Institute for Health Research HTA Programme (project number 16/60/01)

This project was also supported by the National Institute for Health Research, via Cochrane Infrastructure funding to the Cochrane Gynaecological, Neuro-oncology and Orphan Cancer Group. The views and opinions expressed therein are those of the authors and do not necessarily reflect those of the Systematic Reviews Programme, NIHR, NHS or the Department of Health.

\section{R E F E R E N C E S}

\section{Additional references}

\section{Aluwini 2015}

Aluwini S, Pos F, Schimmel E, van Lin E, Krol S, van der Toorn PP, et al. Hypofractionated versus conventionally fractionated radiotherapy for patients with prostate cancer (HYPRO): acute toxicity results from a randomised noninferiority phase 3 trial. Lancet Oncology 2015;16(3): $274-83$.

Andreyev 2007

Andreyev J. Gastrointestinal symptoms after pelvic radiotherapy: a new understanding to improve management of symptomatic patients. Lancet Oncology 2007;8(11): 1007-17.

\section{Andreyev 2012}

Andreyev HJ, Davidson SE, Gillespie C, Allum WH, Swarbrick E. Practice guidance on the management of acute and chronic gastrointestinal problems arising as a result of treatment for cancer. Gut 2012;61(2):179-92.

Arcangeli 2010

Arcangeli G, Saracino B, Gomellini S, Petrongari MG, Arcangeli S, Sentinelli S, et al. A prospective phase III randomized trial of hypofractionation versus conventional fractionation in patients with high-risk prostate cancer. International Journal of Radiation Oncology, Biology, Physics 2010;78(1):11-8.

Barnett 2011

Barnett GC, De Meerleer G, Gulliford SL, Sydes MR, Elliott RM, Dearnaley DP. The impact of clinical factors on the development of late radiation toxicity: results from the
Medical Research Council RT01 trial (ISRCTN47772397). Clinical Oncology 2011;23(9):613-24.

BNF 2016

Joint Formulary Committee. British National Formulary (BNF) 72. London: BMJ Publishing Group Ltd and Royal Pharmaceutical Society, 2016.

Bossi 2016

Bossi A, Blanchard P. Hypofractionation for prostate cancer: a word of caution. Lancet Oncology 2016;17(4):406-7.

Both 2012

Both S, Deville C, Bui V, Kang-Hsin Wang K, Vapiwala N. Emerging evidence for the role of an endorectal balloon in prostate radiation therapy. Translational Cancer Research 2012;1(3):227-35.

\section{Buchi 1991}

Buchi K, Moore J, Hrushesky W, Sothern R, Rubin N. Circadian rhythm of cellular proliferation in the human rectal mucosa. Gastroenterology 1991;101(2):410-5.

\section{CanRes 2016}

Cancer Research UK. What radiotherapy is. www.cancerresearchuk.org/about-cancer/cancers-ingeneral/treatment/radiotherapy/about (accessed 26 September 2016).

\section{CCS 2016}

Canadian Cancer Society. Conformal radiation therapy. www.cancer.ca/en/cancer-information/diagnosis-andtreatment/radiation-therapy (accessed 13 July 2016). 


\section{CHHiP 2016}

Dearnaley D, Syndikus I, Mossop H, Khoo V, Birtle A, Bloomfield D, et al. Conventional versus hypofractionated High-dose intensitiy-modulated radiotherapy for prostate cancer: 5-year outcomes of the randomised, non-inferiority, phase 3 CHHiP trial. Lancet Oncology 2016;17(8): 1047-60.

\section{CTCAE 2010}

National Cancer Institute. Common Terminology Criteria for Adverse Events (CTCAE) version 4.03. evs.nci.nih.gov/ftp1/CTCAE/CTCAE_4.03_2010-06-14_ QuickReference_8.5x11.pdf (accessed 7 July 2016).

Deeks 2001

Deeks JJ, Altman DG, Bradburn MJ. Statistical methods for examining heterogeneity and combining results from several studies in meta-analysis. In: Egger M, Davey Smith G, Altman DG editor(s). Systematic Reviews in Health Care: Meta-Analysis in Context. 2nd Edition. London: BMJ Publication Group, 2001.

Denham 2002

Denham J, Hauer-Jensen M. The radiotherapeutic injury - a complex 'wound'. Radiotherapy Oncology 2002;63(2): $129-45$.

Dennert 2006

Dennert G, Horneber M. Selenium for alleviating the side effects of chemotherapy, radiotherapy and surgery in cancer patients. Cochrane Database of Systematic Reviews 2006, Issue 3. [DOI: 10.1002/14651858.CD005037.pub2]

Devereux 1988

Devereux D, Chandler J, Eisenstat T, Zinkin L. Efficacy of an absorbable mesh in keeping the small bowel out of the human pelvis after surgery. Diseases of the Colon and Rectum 1988;31(1):17-21.

EPOC 2015

Effective Practice, Organisation of Care (EPOC). EPOC Resources for review authors. epoc.cochrane.org/epocspecific-resources-review-authors (accessed 6 July 2016).

Frazzoni 2015

Frazzoni L, La Marca M, Guido A, Morganti AG, Bazzoli F, Fuccio L. Pelvic radiation disease: Updates on treatment options. World Journal of Clinical Oncology 2015;6(6): $272-80$.

Fuhr 2015

Fuhr L, Abreu M, Pett P, Relógio A. Circadian systems biology: When time matters. Computational and Structural Biotechnology Journal 2015;13:417-26.

\section{GLOBOCAN 2012}

International Agency for Research on Cancer. GLOBOCAN 2012: Estimated cancer incidence, mortality and prevalence worldwide in 2012. globocan.iarc.fr/Pages/fact_sheets_ cancer.aspx (accessed $14 \mathrm{Jul} 2016$ ).

Hall 2016

Hall S, Rudrawar S, Zunk M, Bernaitis N, Arora D, McDermott $\mathrm{M}$, et al. Protection against radiotherapyinduced toxicity. Antioxidants 2016;5(3):E22. [DOI: 10.3390/antiox5030022]

\section{Henson 2013}

Henson CC, Burden S, Davidson SE, Lal S. Nutritional interventions for reducing gastrointestinal toxicity in adults undergoing radical pelvic radiotherapy. Cochrane Database of Systematic Reviews 2013, Issue 11. [DOI: 10.1002/ 14651858.CD009896.pub2]

Higgins 2003

Higgins JPT, Thompson SG, Deeks JJ, Altman DG. Measuring inconsistency in meta-analyses. BMJ 2003;327 (7414):557-60.

Higgins 2011

Higgins JPT, Green S (editors). Cochrane Handbook for Systematic Reviews of Interventions Version 5.1.0 [updated March 2011]. The Cochrane Collaboration, 2011. Available from www.cochrane-handbook.org.

\section{Hoffman 2014}

Hoffman KE, Voong KR, Pugh TJ, Skinner H, Levy LB, Takiar V, et al. Risk of late toxicity in men receiving dose-escalated hypofractionated intensity modulated prostate radiation therapy: results from a randomized trial. International Journal of Radiation Oncology, Biology, Physics 2014;88(5):1074-84.

Ijiri 1990

Ijiri K, Potten C. The circadian rhythm for the number and sensitivity of radiation-induced apoptosis in the crypts of mouse small intestine. International Journal of Radiation Biology 1990;58(1):165-75.

Jahraus 2005

Jahraus CD, Bettenhausen D, Malik U, Sellitti M, St Clair WH. Prevention of acute radiation-induced proctosigmoiditis by balsalazide: a randomized, doubleblind, placebo controlled trial in prostate cancer patients. International Journal of Radiation Oncology, Biology, Physics 2005;63(5):1483-7.

\section{Khalid 2006}

Khalid U, McGough C, Hackett C, Blake P, Harrington $\mathrm{KJ}$, Khoo VS, et al. A modified inflammatory bowel disease questionnaire and the Vaizey Incontinence questionnaire are more sensitive measures of acute gastrointestinal toxicity during pelvic radiotherapy than RTOG grading. International Journal of Radiation Oncology, Biology, Physics 2006;64(5):1432-41.

Kilic 2001

Kilic D, Ozenirler S, Egehan I, Dursun A. Sulfasalazine decreases acute gastrointestinal complications due to pelvic radiotherapy. Annals of Pharmacotherapy 2001;35(7-8): 806-10.

\section{Kligler 2008}

Kligler B, Cohrsson A. Probiotics. Family Physician 2008; 78:1073-8.

\section{Koontz 2015}

Koontz BF, Bossi A, Cozzarini C, Wiegel T, D’Amico A. A systematic review of hypofractionation for primary management of prostate cancer. European Urology 2015;68 (4):683-91. 


\section{Kouvaris 2007}

Kouvaris JR, Kouloulias VE, Vlahos LJ. Amifostine: the first selective-target and broad-spectrum radioprotector. Oncologist 2007;12(6):738-47.

\section{Krol 2014}

Krol R, Smeenk RJ, van Lin EN, Yeoh EE, Hopman WP. Systematic review: anal and rectal changes after radiotherapy for prostate cancer. International Journal of Colorectal Disease 2014;29(3):273-83.

\section{Lischalk 2016}

Lischalk JW, Kaplan ID, Collins SP. Stereotactic body radiation therapy for localized prostate cancer. Cancer Journal 2016;22(4):307-13.

\section{Michalski 2010}

Michalski JM, Gay H, Jackson A, Tucker SL, Deasy JO. Radiation dose-volume effects in radiation-induced rectal injury. International Journal of Radiattion Oncology, Biology, Physics 2010;76(3 Suppl):S123-9.

\section{Moon 2017}

Moon DH, Efstathiou JA, Chen RC. What is the best way to radiate the prostate in 2016?. Urologic Oncology 2017;35 (2):59-68. [DOI: 10.1016/j.urolonc.2016.06.002]

\section{Morris 2015}

Morris KA, Haboubi NY. Pelvic radiation therapy: Between delight and disaster. World Journal of Gastrointestinal Surgery 2015;7(11):279-88.

\section{Muls 2014}

Muls AC. Acta Oncologica Lecture. Gastrointestinal consequences of cancer treatment and the wider context: a bad gut feeling. Acta Oncologica 2014;53(3):297-306.

\section{NCAT 2012}

National Cancer Action Team. National radiotherapy implementation group report: Image guided radiotherapy (IGRT). www.natcansat.nhs.uk\%2Fdlhandler.ashx $\% 3 \mathrm{Fd} \% 3 \mathrm{D}$ pubs $\%$ usg=AFQjCNHwVBzIpkFBJ4xyx0uaZqSUZ62KEw\& cad=rja (accessed 13 July 2016).

\section{Norkus 2013}

Norkus D, Karklelyte A, Engels B, Versmessen H, Griskevicius R, De Ridder M, et al. A randomized hypofractionation dose escalation trial for high risk prostate cancer patients: Interim analysis of acute toxicity and quality of life in 124 patients. Radiation Oncology 2013;8: 206.

Nout 2010

Nout RA, Smit VT, Putter H, Jurgenliemk-Schulz IM, Jobsen JJ, Lutgens LC, et al. Vaginal brachytherapy versus pelvic external beam radiotherapy for patients with endometrial cancer of high-intermediate risk (PORTEC2): an open-label, non-inferiority, randomised trial. Lancet 2010;375(9719):816-23.

O'Brien 2002

O’Brien PC, Franklin CI, Poulsen MG, Joseph DJ, Spry NS, Denham JW. Acute symptoms, not rectally administered sucralfate, predict for late radiation proctitis: longer term follow-up of a phase III trial - Trans-Tasman Radiation
Oncology Group. International Journal of Radiation

Oncology, Biology, Physics 2002;54(2):442-9.

\section{Olopade 2005}

Olopade FA, Norman A, Blake P, Dearnaley DP, Harrington $\mathrm{KJ}$, Khoo V, et al. A modified Inflammatory Bowel Disease questionnaire and the Vaizey Incontinence questionnaire are simple ways to identify patients with significant gastrointestinal symptoms after pelvic radiotherapy. British Journal of Cancer 2005;92(9):1663-70.

\section{Pollack 2013}

Pollack A, Walker G, Horwitz EM, Price R, Feigenberg $S$, Konski A, et al. Randomized trial of hypofractionated external-beam radiotherapy for prostate cancer. Journal of Clinical Oncology 2013;31(31):3860-8.

\section{RevMan 2014 [Computer program]}

The Nordic Cochrane Centre, The Cochrane Collaboration. Review Manager (RevMan). Version 5.3. Copenhagen: The Nordic Cochrane Centre, The Cochrane Collaboration, 2014.

\section{Rodier 1991}

Rodier J, Janser J, Rodier D, Dauplar J, Kauffmann P, Le Bouedec G, et al. Prevention of radiation enteritis by an absorbable polyglycolic acid mesh sling. A 60-case multicentric study. Cancer 1991;68(12):2545-9.

\section{Schünemann 2011}

Schünemann HJ, Oxman AD, Vist GE, Higgins JP, Deeks JJ, Glasziou P, et al. Chapter 12: Interpreting results and drawing conclusions. Cochrane Handbook for Systematic Reviews of Interventions. Version 5.1.0 [updated March 2011]. The Cochrane Collaboration. Available from www.cochrane-handbook.org 2011.

\section{Shadad 2013}

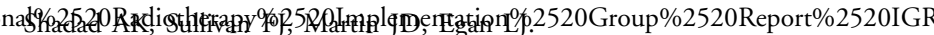
Gastrointestinal radiation injury: prevention and treatment. World Journal of Gastroenterology 2013;19(2):199-208.

\section{Shukla 2010}

Shukla P, Gupta D, Bisht SS, Pant MC, Bhatt ML, Gupta $\mathrm{R}$, et al. Circadian variation in radiation-induced intestinal mucositis in patients with cervical carcinoma. Cancer 2010; 116(8):2031-5.

\section{Soh 2015}

Soh F-Y, James ML, Hickey BE, Daly T, Jeffery M, See $\mathrm{AM}$, et al. Altered radiation fractionation schedules for clinically localised and locally advanced prostate cancer. Cochrane Database of Systematic Reviews 2015, Issue 1. [DOI: 10.1002/14651858.CD011462]

\section{Sorbe 2012}

Sorbe B, Horvath G, Andersson H, Boman K, Lundgren C, Pettersson B. External pelvic and vaginal irradiation versus vaginal irradiation alone as postoperative therapy in medium-risk endometrial carcinoma - A prospective randomized study. International Journal of Radiation Oncology, Biology, Physics 2012;82(3):1249-55. 
Stacey 2014

Stacey R, Green JT. Radiation-induced small bowel disease: latest developments and clinical guidance. Therapeutic Advances in Chronic Disease 2014;5(1):15-29.

Sun 2014

Sun JX, Yang N. Role of octreotide in post chemotherapy and/or radiotherapy diarrhea: Prophylaxis or therapy?. AsiaPacific Journal of Clinical Oncology 2014;10(2):e108-13.

Theis 2010

Theis V, Sripadam R, Ramani V, Lal S. Chronic radiation enteritis. Clinical Oncology 2010;22(1):70-83.

Van de Wetering 2013

Van de Wetering FT, Heus P, Verleye L, Van Tienhoven G, Scholten RJPM. Probiotics for the prevention or treatment of chemotherapy or radiotherapy related diarrhoea in cancer patients. Cochrane Database of Systematic Reviews 2013, Issue 12. [DOI: 10.1002/14651858.CD008831.pub2]

Van de Wetering 2016

Van de Wetering FT, Verleye L, Andreyev HJ, Maher J, Vlayen J, Pieters BR, et al. Non-surgical interventions for late rectal problems (proctopathy) of radiotherapy in people who have received radiotherapy to the pelvis. Cochrane Database of Systematic Reviews 2016, Issue 4. [DOI: 10.1002/14651858.CD003455.pub2]

Wang 2007

Wang J, Boerma M, Fu Q, Kulkarni A, Fink LM, HauerJensen M. Simvastatin ameliorates radiation enteropathy development after localized, fractionated irradiation by a protein C-independent mechanism. International Journal of Radiation Oncology, Biology, Physics 2007;68(5):1483-90.

Wedlake 2012

Wedlake LJ, Silia F, Benton B, Lalji A, Thomas K, Dearnaley DP, et al. Evaluating the efficacy of statins and ACEinhibitors in reducing gastrointestinal toxicity in patients receiving radiotherapy for pelvic malignancies. European Journal of Cancer 2012;48(14):2117-24.

Wedlake 2013

Wedlake LJ, Shaw C, Whelan K, Andreyev HJ. Systematic review: the efficacy of nutritional interventions to counteract acute gastrointestinal toxicity during therapeutic pelvic radiotherapy. Alimentary Pharmacology \& Therapeutics 2013;37(11):1046-56.

Weisendanger-Wittmer 2012

Wiesendanger-Wittmer EM, Sijtsema NM, Muijs CT, Beukema JC. Systematic review of the role of a belly board device in radiotherapy delivery in patients with pelvic malignancies. Radiotherapy and Oncology 2012;102(3): 325-34.

\section{Yu 2016}

Yu T, Zhang Q, Zheng T, Shi H, Liu Y, Feng S, et al. The effectiveness of intensity modulated radiation therapy versus three-dimensional radiation therapy in prostate cancer: a meta-analysis of the literatures. PLoS ONE 2016;11(5): e0154499.

* Indicates the major publication for the study

\section{A P P E N D I C E S}

\section{Appendix I. MEDLINE search strategy}

1. exp Radiotherapy/

2. radiotherapy.fs.

3. (radiotherap* ${ }^{*}$ or radiation or irradiat*).mp.

4. 1 or 2 or 3

5. Radiation Effects/

6. exp Radiation Injuries/

7. adverse effects.fs.

8. adverse effect*.mp.

9. toxic*.mp.

10. 5 or 6 or 7 or 8 or 9

11. exp Gastrointestinal Diseases/

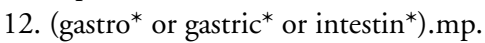

13. $\operatorname{exp~Nausea/~}$

14. exp Vomiting/

15. (nause* or vomit* or emesis).mp.

16. exp Diarrhea/

Interventions to reduce acute and late adverse gastrointestinal effects of pelvic radiotherapy (Protocol)

Copyright $\Subset 2017$ The Cochrane Collaboration. Published by John Wiley \& Sons, Ltd. 
17. diarrh*.mp.

18. Fecal Incontinence/

19. exp Abdominal Pain/

20. (rect* adj5 bleed*).mp.

21. (abdom* adj5 pain).mp.

22. Flatulence/

23. flatulen*.mp.

24. ((fecal or faecal) adj5 urgency).mp.

25. (bloat* or tenesmus).mp.

26. 11 or 12 or 13 or 14 or 15 or 16 or 17 or 18 or 19 or 20 or 21 or 22 or 23 or 24 or 25

27.4 and 10 and 26

28. randomized controlled trial.pt.

29. controlled clinical trial.pt.

30. randomized.ab.

31. placebo.ab.

32. clinical trials as topic.sh.

33. randomly.ab.

34. trial.ti.

35.28 or 29 or 30 or 31 or 32 or 33 or 34

36. 27 and 35

Key:

$\mathrm{mp}=$ title, abstract, original title, name of substance word, subject heading word, keyword heading word, protocol supplementary concept word, rare disease supplementary concept word, unique identifier

$\mathrm{pt}=$ publication type

$\mathrm{ab}=\mathrm{abstract}$

ti=title

\section{Appendix 2. Assessment of Risk of Bias}

\section{(I) Random sequence generation}

- Low risk of bias e.g. participants assigned to treatments on basis of a computer-generated random sequence or a table of random numbers

- High risk of bias e.g. participants assigned to treatments on basis of date of birth, clinic id-number or surname, or no attempt to randomise participants

- Unclear risk of bias e.g. not reported, information not available

\section{(2) Allocation concealment}

- Low risk of bias e.g. where the allocation sequence could not be foretold

- High risk of bias e.g. allocation sequence could be foretold by patients, investigators or treatment providers

- Unclear risk of bias e.g. not reported

\section{(3) Blinding of participants and personnel}

- Low risk of bias if participants and personnel were adequately blinded

- High risk of bias if participants were not blinded to the intervention that the participant received

- Unclear risk of bias if this was not reported or unclear 
(4) Blinding of outcomes assessors (self-reported or investigator-assessed)

- Low risk of bias if outcome assessors were adequately blinded

- High risk of bias if outcome assessors were not blinded to the intervention that the participant received

- Unclear risk of bias if this was not reported or unclear.

\section{(4) Incomplete outcome data}

We will record the proportion of participants whose outcomes were not reported at the end of the study. We will code a satisfactory level of loss to follow-up for each outcome as:

- Low risk of bias, if fewer than $20 \%$ of patients were lost to follow-up and reasons for loss to follow-up were similar in both treatment arms

- High risk of bias, if more than $20 \%$ of patients were lost to follow-up or reasons for loss to follow-up differed between treatment arms

- Unclear risk of bias if loss to follow-up was not reported

\section{(5) Selective reporting of outcomes}

- Low risk of bias e.g. review reports all outcomes specified in the protocol

- High risk of bias e.g. It is suspected that outcomes have been selectively reported

- Unclear risk of bias e.g. It is unclear whether outcomes had been selectively reported

\section{(6) Other bias}

- Low risk of bias, i.e.no other source of bias suspected and the trial appears to be methodologically sound

- High risk of bias - we suspect that the trial was prone to an additional bias

- Unclear risk of bias - we are uncertain whether an additional bias may have been present

\section{Appendix 3. SoF example}

IMRT compared with 3DCRT to reduce adverse GI effects of radiotherapy

Patient or population: people with urological, gynaecological or colorectal cancer

Settings: any

Intervention: intensity-modulated radiotherapy (IMRT)

Comparison: 3DCRT

\begin{tabular}{|c|c|c|c|c|c|c|}
\hline \multirow[t]{3}{*}{ Outcomes } & \multicolumn{2}{|c|}{$\begin{array}{l}\text { Illustrative comparative risks* } \\
(95 \% \mathrm{CI})\end{array}$} & \multirow[t]{3}{*}{$\begin{array}{l}\text { Relative effect } \\
(95 \% \text { CI })\end{array}$} & \multirow{3}{*}{$\begin{array}{l}\text { No of Partici- } \\
\text { pants } \\
\text { (studies) }\end{array}$} & \multirow{3}{*}{$\begin{array}{l}\text { Quality of the } \\
\text { evidence } \\
\text { (GRADE) }\end{array}$} & \multirow[t]{3}{*}{ Comments } \\
\hline & Assumed risk & $\begin{array}{l}\text { Corresponding } \\
\text { risk }\end{array}$ & & & & \\
\hline & 3DCRT & IMRT & & & & \\
\hline $\begin{array}{l}\text { Mean GI symp- } \\
\text { tom scores } \\
\text { [vari- }\end{array}$ & $\begin{array}{l}\text { Early effects: } \\
\text { [Up to } 3 \text { months } \\
\text { after RT, the }\end{array}$ & $\begin{array}{l}\text { [Up to } \\
3 \text { months] after } \\
\text { RT, the mean GI }\end{array}$ & & $\begin{array}{l}\text { [value }] \\
\text { ([value }])\end{array}$ & $\begin{array}{l}\text { [Insert as } \\
\text { appropriate] } \\
\oplus \bigcirc \bigcirc \bigcirc\end{array}$ & $\begin{array}{l}\text { Possibly } \\
\text { discuss the sub- } \\
\text { group findings/ }\end{array}$ \\
\hline
\end{tabular}




\begin{tabular}{|c|c|c|c|c|c|c|}
\hline \multirow[t]{3}{*}{$\begin{array}{l}\text { ous scales includ- } \\
\text { ing IBDQ-BD, . } \\
\text {..] }\end{array}$} & $\begin{array}{l}\text { mean GI symp- } \\
\text { tom score ranged } \\
\text { across control } \\
\text { groups from } \\
\text { [value][measure]] }\end{array}$ & $\begin{array}{l}\text { symptom score } \\
\text { in the interven- } \\
\text { tion groups was } \\
\text { [value] [lower/ } \\
\text { higher] } \\
\text { [(value to value } \\
\text { lower/higher)] }\end{array}$ & & & $\begin{array}{l}\text { very low } \\
\oplus \oplus \bigcirc \bigcirc \\
\text { low } \\
\oplus \oplus \oplus \bigcirc \\
\text { moderate } \\
\oplus \oplus \oplus \oplus \\
\text { high }\end{array}$ & $\begin{array}{l}\text { effects in this col- } \\
\text { umn }\end{array}$ \\
\hline & $\begin{array}{l}\text { Late effects: [At } \\
2 \text { years after RT], } \\
\text { the } \\
\text { mean GI symp- } \\
\text { tom score ranged } \\
\text { across control } \\
\text { groups from } \\
\text { [value][measure] }\end{array}$ & $\begin{array}{l}\text { [At } 2 \text { years] after } \\
\text { RT, the mean GI } \\
\text { symptom score } \\
\text { in the interven- } \\
\text { tion groups was } \\
\text { [value] [lower/ } \\
\text { higher] } \\
\text { [(value to value } \\
\text { lower/higher)] }\end{array}$ & & $\begin{array}{l}\text { [value }] \\
\text { ([value }])\end{array}$ & & \\
\hline & $\begin{array}{l}\text { Late effects: [At } \\
5 \text { years after RT], } \\
\text { the } \\
\text { mean GI symp- } \\
\text { tom score ranged } \\
\text { across control } \\
\text { groups from } \\
\text { [value][measure] }\end{array}$ & $\begin{array}{l}\text { [At } 5 \text { years] after } \\
\text { RT, the mean GI } \\
\text { symptom score } \\
\text { in the interven- } \\
\text { tion groups was } \\
\text { [value] [lower/ } \\
\text { higher] } \\
\text { [(value to value } \\
\text { lower/higher)] }\end{array}$ & & $\begin{array}{l}\text { [value }] \\
\text { ([value }] \text { ) }\end{array}$ & & \\
\hline \multirow[t]{3}{*}{$\begin{array}{l}\text { Moderate or se- } \\
\text { vere GI symp- } \\
\text { toms }\end{array}$} & $\begin{array}{l}\text { Early effects: } \\
\text { [Up to } 3 \text { months } \\
\text { after RT]: } \\
\text { [value] per } 1000\end{array}$ & $\begin{array}{l}\text { [Up } \\
\text { to } 3 \text { months] af- } \\
\text { ter RT: } \\
\text { [value] per } \\
\mathbf{1 0 0 0} \\
\text { ([value] } \\
\text { [value]) }\end{array}$ & $\begin{array}{l}\text { RR } \\
\text { [value] ([value] } \\
\text { to [value]) }\end{array}$ & $\begin{array}{l}\text { [value] } \\
\text { ([value]) }\end{array}$ & & \\
\hline & $\begin{array}{l}\text { Late effects: [At } 2 \\
\text { years] after RT: } \\
\text { [value] per } 1000\end{array}$ & $\begin{array}{l}\text { [At 2 years] after } \\
\text { RT: } \\
\text { [value] } \\
\mathbf{1 0 0 0} \\
\text { ([value] } \\
\text { [value] }\end{array}$ & $\begin{array}{l}\text { RR } \\
\text { [value] ([value] } \\
\text { to [value]) }\end{array}$ & $\begin{array}{l}\text { [value] } \\
\text { ([value]) }\end{array}$ & & \\
\hline & $\begin{array}{l}\text { Late effects: } \text { [At } 5 \\
\text { years] after RT: } \\
\text { [value] per } 1000\end{array}$ & $\begin{array}{l}\text { [At } 5 \text { years] } \text { after } \\
\text { RT: } \\
\text { [value] } \\
\mathbf{1 0 0 0} \\
\text { ([value] }\end{array}$ & $\begin{array}{l}\text { RR } \\
\text { [value] ([value] } \\
\text { to }[\text { value] })\end{array}$ & $\begin{array}{l}\text { [value }] \\
\text { ([value }])\end{array}$ & & \\
\hline
\end{tabular}


[value])

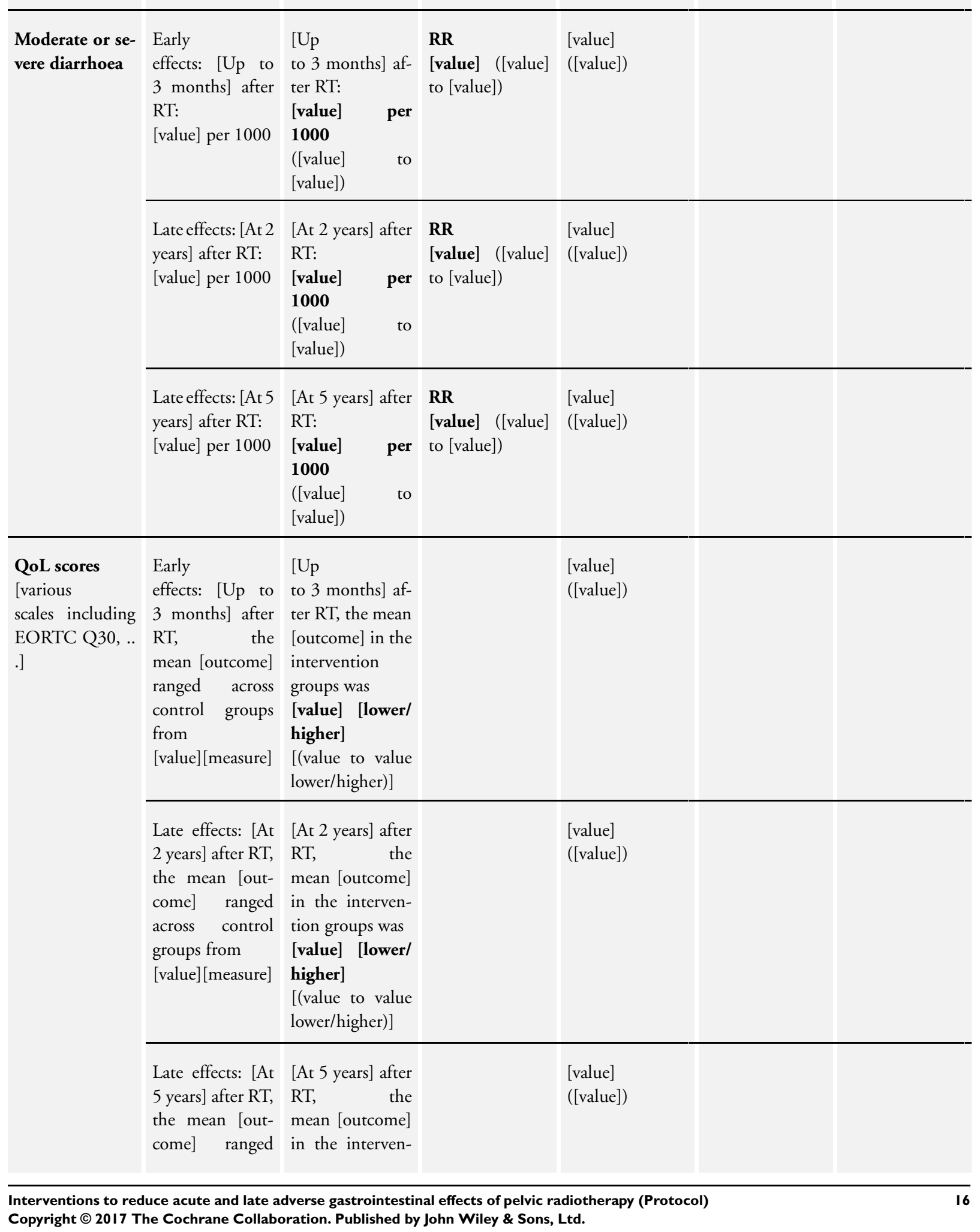




$$
\begin{array}{ll}
\text { across control } & \text { tion groups was } \\
\text { groups from } & \text { [value] [lower/ } \\
\text { [value][measure] } & \begin{array}{l}
\text { higher] } \\
\text { [(value to value } \\
\text { lower/higher)] }
\end{array}
\end{array}
$$

*The basis for the assumed risk (e.g. the median control group risk across studies) is provided in footnotes. The corresponding risk (and its 95\% confidence interval) is based on the assumed risk in the comparison group and the relative effect of the intervention (and its 95\% CI).

CI: Confidence interval; RR: Risk Ratio; [other abbreviations, eg. OR, etc]

GRADE Working Group grades of evidence

High quality: Further research is very unlikely to change our confidence in the estimate of effect.

Moderate quality: Further research is likely to have an important impact on our confidence in the estimate of effect and may change the estimate.

Low quality: Further research is very likely to have an important impact on our confidence in the estimate of effect and is likely to change the estimate.

Very low quality: We are very uncertain about the estimate.

\section{CONTRIBUTIONS OFAUTHORS}

Theresa Lawrie wrote the first draft of the protocol. All authors advised on and approved the final version of the protocol.

\section{DECLARATIONSOF INTEREST}

Theresa Lawrie: none declared

Jervoise Andreyev: none declared

John Green: none declared

Sorrel Burden: none declared

Caroline Henson: none declared

Simon Lai: none declared

Mark Beresford: none declared

Susan Davidson: none declared 


\section{SOURCES OF SUPPORT}

\section{Internal sources}

- No sources of support supplied

\section{External sources}

- National Institute for Health Research HTA Programme (project number 16/60/01), UK. 